\title{
PENGEMBANGAN MEDIA PICTURES MOVEMENT UNTUK PEMBELAJARAN MENULIS PARAGRAF
}

\author{
Sa'id Arizal dan Ngatmain \\ SMA Islam Miftahul Ulum Pamekasan, Universitas Muhammadiyah Surabaya \\ said.arizal@yahoo.com
}

\begin{abstract}
ABSTRAK
Penelitian ini bertujuan untuk mendeskripsikan (1) proses pengembangan media pictures movement untuk pembelajaran menulis paragraf siswa kelas XII SMA Islam Miftahul Ulum. (2) efektifitas media pictures movement untuk pembelajaran menulis paragraf siswa kelas XII SMA Islam Miftahul Ulum yang dikembangkan. (3) kepraktisan media pictures movement untuk pembelajaran menulis paragraf siswa kelas XII SMA Islam Miftahul Ulum yang dikembangkan. Penelitian ini menggunakan penelitian Research \& Development ( $\mathrm{R} \& \mathrm{D})$, yaitu rangkaian proses atau langkah-langkah dalam rangka mengembangkan suatu produk baru atau memperbaiki produk-produk yang telah ada agar dapat dipertanggungjawabkan. Responden dalam penelitian ini adalah siswa kelas XII SMA Islam Miftahul Ulum yang berjumlah 20 peserta didik. Teknik pengumpulan data dengan instrument, wawancara, angket, dan tes. Sedangkan teknik analisis data menggunakan analisis data deskriptif. Dari hasil penelitian diketahui bahwa diperoleh hasil penelitian untuk uji validasi produk/media ahli media 1 yaitu 4.00/baik, ahli media 2 yaitu 4.15/baik. Ahli materi yaitu 4.22/baik. Pengguna (guru 1) yaitu 4.16/baik, (guru 2) yaitu 4.06/baik. Uji coba skala kecil untuk penilaian proses yaitu 4.00/sangat baik, kesatuan yaitu 3.80/sangat baik, koherensi yaitu 2.00/baik, kelengkapan yaitu 3.40/sangat baik. Untuk uji coba skala besar untuk penilaian proses yaitu 3.90/sangat baik, kesatuan yaitu 3.55/sangat baik, koherensi mendapat yaitu 3.50/sangat baik, kelengkapan mendapat yaitu 3.35/sangat baik. Sedangkan untuk angket respon siswa memperoleh jumlah 223 pilihan (setuju) dan dari hasil wawancara dengan guru Bahasa Indonesia memperoleh kesimpulan bahwa media pictures movement ini telah guru tersebut merasa terbantu dalam pemberian materi menulis paragraf kepada siswa karena media pictures movement ini adalah media elektronik yang fleksibel dan variatif sehingga pembelajaran tidak monoton dan tercipta kelas yang kondusif, menyenangkan serta praktis.
\end{abstract}

Kata Kunci: media, pictures movement, menulis paragraf

ABSTRACT

This research aims to describe (1) the process of developing a media pictures movement for learning writing paragraph at class XII Islamic High School student Miftahul Ulum. (2) The effectiveness of the media pictures movement for learning writing paragraph class XII Islamic High School students Miftahul Ulum which is developed, and also (3) the practicality of the media 
pictures movement for learning writing paragraph class XII Islamic High School students Miftahul Ulum. This research uses Research \& Development (R \& D), which is a series of processes or steps in order to develop a new product or improve existing products in order to be accountable. Respondents in this study are students of class XII SMA Islam Miftahul Ulum which amounted to 20 students. Data collection techniques are interviews, questionnaires, and tests. While the technique of data analysis was a descriptive data analysis. The results show that the validation test of media expert 1 is 4.00 with the category of well, the media expert 2 is 4.15 with the category of good; the material expert is 4.22 with the category of good; the user 1 (teacher 1) is 4.16 with the category of good, and the user 2 (teacher 2) is 4.06 with the category of good. Small scale test for process assessment is 4.00 with the category of very good, unity is 3.80 with the category of very good, coherence is 2.00 with the category of good, and completeness is 3.40 with the category of very good. For largescale trials for process assessment i.e. of 3.90 which is excellent, unity of 3.55 which is very good, coherence of 3.50 which is very good, completeness gets of 3.35 which is very good. As for the questionnaire, the students received 223 votes (agree) and from the interviews with the Indonesian teachers, they concluded that the media pictures movement has helped them to give the material of writing paragraphs to the students because the media pictures movement is a flexible and varied electronic media that make learning not monotonous and create a conducive, fun and practical class.

Keywords: media, pictures movement, paragraph writing

PENDAHULUAN
Pembelajaran yang efektif merupakan pembelajaran yang didukung oleh sarana dan prasarana yang menunjang proses pembelajaran di dalam kelas. Salah satu sarana pendukung terhadap pembelajaran yang efektif adalah tersedianya bahan ajar yang relevan karena bahan ajar merupakan segala bahan (baik informasi, alat, maupun teks) yang disusun secara sistematis, yang menampilkan sosok utuh dari kompetensi yang akan dikuasai siswa dan digunakan dalam proses pembelajaran dengan tujuan perencanaan dan penelaahan implementasi pembelajaran, namun hampir semua bahan ajar yang berbentuk buku paket tidak mempunyai materi pendukung yang disertai contoh dengan gambar-gambar yang riil. Seperti yang dikemukakan oleh Benny (2017:23) bahwa media gambar berperan dapat mengurangi terjadinya kesalahan interpretasi dalam mempelajari informasi dan pengetahuan yang bersifat abstrak.

Banyak aspek yang sebenarnya harus dilakukan untuk melakukan sebuah perubahan supaya transformasi materi dari buku paket kepada siswa dapat berjalan dengan baik yaitu salah satunya adalah memberikan contoh. Pemberian contoh adalah bentuk stimulus bagi peserta didik agar lebih memahami materi yang diberikan seperti halnya materi menulis paragraf. 
Dalam materi menulis paragraf yang terdapat pada buku paket tidak pernah ditemukan sebuah contoh konkrit seperti halnya gambar yang mendukung pada tema-tema tertentu. Tidak terdapatnya sebuah gambar maka berdampak pada sulitnya peserta didik untuk bisa menulis suatu paragraf dengan tema tertentu seperti paragraf deduktif, induktif, campuran dan interatif karena aspek menulis adalah aspek keterampilan yang mempunyai tingkat kesulitan yang signifikan dibandingkan dengan aspek keterampilan bahasa yang lain.

Seperti yang disampaikan oleh Nurgiantoro (1995: 294) bahwa "dibandingkan dengan kemampuan berbahasa yang lain, keterampilan menulis sulit dikuasai bahkan oleh penutur asli bahasa yang bersangkutan sekalipun." Sebenarnya kecakapan menulis dapat dimiliki oleh semua orang yang pernah menduduki bangku sekolah, karena menulis atau mengarang pada hakikatnya merupakan pemindahan pikiran atau perasaan kedalam bentuk lambang-lambang bahasa. Demikian halnya dengan pendapat Suria Miharja (1996:2) yang menjelaskan bahwa "menulis adalah berkomunikasi mengungkapkan pikiran, perasaan dan kehendak kepada orang lain secara tertulis."

Berdasarkan observasi yang dilakukan salah satu sekolah di Jawa Timur (SMA Islam Miftahul Ulum) dalam mengidentifikasi kesulitan belajar pada materi menulis paragraf berdasarkan kalimat utama dengan melakukan wawancara kepada siswa, maka dapat diidentifikasi masalah yaitu yang pertama sulit menemukan gagasan. Kesulitan menemukan ide dalam menulis paragraf adalah pemberian instruksi atau tugas yang diberikan guru dalam membuat paragraf tidak fokus pada satu masalah yang akan ditulis (instruksi) bersifat umum. Dari hal tersebut timbul kerancuan dalam diri siswa ketika akan menulis paragraf sehingga berakibat pada pola pikir siswa yang cenderung lama dalam menemukan ide.

Permasalahan yang kedua adalah sulit menyusun kalimat dengan paragraf yang padu. Hal tersebut disebabkan karena kurangnya pengetahuan siswa terhadap pengalaman-pengalaman di luar lingkungan ketika akan direlevansikan dengan menulis paragraf yang diintruksikan oleh guru dengan tema tertentu. Minimnya sebuah pengalaman secara tidak langsung akan menghambat proses instruksi di dalam menulis sebuah paragraf dengan tema tertentu.

Ketiga adalah kesulitan menggunakan konjungsi. Penggunaan konjungsi dalam menulis suatu paragraf sebenarnya mudah untuk dipelajari. Akan tetapi bagi para siswa yang kesulitan dalam menggunakan konjungsi disebabkan karena pengetahuan tentang kondisi riil pada objek tidak ada, jadi perlu adanya sebuah deskripsi tentang instruksi yang akan diberikan kepada peserta didik.

Kekurangan yang keempat adalah kurang memahami penjelasan guru. Hal ini karena kurang menariknya pembelajaran menulis paragraf yang disampaikan oleh guru yang secara tidak langsung ini adalah sebuah hambatan yang dikeluhkan oleh para siswa karena tidak ada inovasi maupun stimulus pembelajaran. 
Faktor yang menjadi kendala dalam memahami penjelasan guru adalah penggunaan metode ceramah yang dilakukan secara terus menerus tanpa ada variasi metode mengajar yang lain karena pada hakikatnya metode pembelajaran tersebut selain harus menyesuaikan dengan bentuk pembelajaran sesuai dengan kompetensi dasar yang dirumuskan ke dalam bentuk indikator juga disertai dengan alat bantu mengajar untuk memperjelas uraian yang disampaikan kepada siswa .

Pembelajaran merupakan pelaksanaan strategi-strategi yang telah dirancang khusus untuk mencapai sebuah tujuan pembelajaran agar belajar bisa lebih efektif, efisien dan terarah. Efektivitas di dalam pembelajaran dapat tercapai dan sangat bergatung dari kemampuan seorang guru untuk mencapai keberhasilan proses pembelajaran tersebut. Dalam pembelajaran di sekolah terdapat pembelajaran yaitu proses tejadinya perubahan pengetahuan, sikap, informasi, kemampuan dan keterampilan yang sifatnya permanen melalui pengalaman.

Metode maupun strategi dalam penyampaian sebuah materi belajar haruslah mempunyai ragam inovasi agar tercipta pembelajaran yang efektif dan tepat sasaran. Maka dari itu, guru wajib melakukan hal tersebut karena mengingat salah satu masalah pokok dalam pembelajaran pada pendidikan formal (sekolah) dewasa ini adalah masih rendahnya daya serap peserta didik.

Kekurangan yang kelima adalah pembelajaran yang masih konvensional. Hal ini tampak dari rerata hasil belajar peserta didik yang senantiasa masih sangat memprihatinkan. Prestasi ini tentu merupakan hasil kondisi pembelajaran yang masih bersifat konvensional dan tidak menyentuh ranah dimensi peserta didik itu sendiri yaitu bagaimana sebenarnya belajar itu (belajar untuk belajar). Dalam arti yang lebih substansial bahwa proses pembelajaran hingga dewasa ini masih memberikan dominasi guru dan tidak memberikan akses bagi anak didik untuk berkembang secara mandiri melalui penemuan dan proses berpikirnya.

Di sisi lain secara empiris berdasarkan dari hasil analisis penelitian terhadap rendahnya hasil belajar peserta didik, hal tersebut disebabkan oleh proses pembelajaran yang masih didominasi oleh pembelajaran tradisional. Pada pembelajaran ini suasana kelas cenderung berpusat kepada guru sehingga siswa menjadi pasif. Kendati demikian, guru lebih suka menerapkan model tersebut sebab tidak memerlukan alat dan bahan praktek yang spesifik, hanya cukup menjelaskan konsep-konsep yang ada pada buku teks atau literatur lain. Oleh sebab itu tidaklah heran jika konsep belajar dan pembelajaran yang dahulu lebih menekankan kepada seorang guru yang harus berjuang keras yang akhirnya terjadi pembelajaran stagnan dan pasif.

Untuk itu dalam perkembangan ilmu pengetahuan dan teknologi dewasa ini yang semakin pesat harus dimanfaatkan dengan baik untuk mendorong segala bentuk upaya-upaya pembaharuan dalam pemanfaatan hasil-hasil teknologi dalam proses belajar. Salah satu inovasi yang menarik untuk mencapai 
perubahan paradigma tersebut adalah penggunaan metode belajar yaitu menggunakan media pembelajaran. Media pembelajaran merupakan segala sesuatu yang dapat digunakan untuk menyalurkan pesan yaitu bahan pembelajaran, sehingga dapat menstimulus atau merangsang bentuk perhatian, pikiran, minat, dan perasaan siswa dalam kegiatan belajar untuk mencapai tujuan pembelajaran tertentu.

Pemakaian media pembelajaran dalam proses pembelajaran dapat membangkitkan keinginan dan minat yang baru, membangkitkan motivasi dan rangsangan kegiatan belajar, dan bahkan membawa pengaruh-pengaruh psikologis terhadap siswa. Penggunaan media pembelajaran pada tahap orientasi pembelajaran akan sangat membantu keefektifan proses pembelajaran dan penyampaian pesan dan isi pelajaran pada saat itu. Selain membangkitkan motivasi dan minat siswa, media pembelajaran juga dapat membantu siswa meningkatkan pemahaman, menyajikan data dengan menarik dan terpercaya, memudahkan penafsiran data, dan memadatkan informasi, Hamalik dalam Arsyad (2016:19-20).

Salah satu media pembelajaran yang dapat dijadikan sebagai langkah inovasi pembelajaran kepada siswa adalah media pembelajaran pictures movement atau dikenal dengan nama animasi. Penerapan media pembelajaran adalah salah satu strategi agar pembelajaran akan lebih variatif, inovatif, dan konstruktif dalam merekonstruksi wawasan pengetahuan dan implementasinya sehingga dapat meningkatkan aktivitas dan kreativitas peserta didik.

Penelitian pengembangan animasi sebelumnya sudah pernah dilakukan oleh beberapa orang peneliti dengan spesifikasi dan karakteristik yang berbeda. Dari beberapa penelitian animasi yang sudah dilakukan, terdapat tiga penelitian yang membahas penelitian pengembangan media pembelajaran menggunakan animasi. Pertama, penelitian pengembangan media pembelajaran teknik animasi 2 dimensi berbasis adobe flash. Dalam penelitian ini mengembangkan teknik pembuatan animasi secara umum dengan menggunakan aplikasi adobe flash yang bisa digunakan sebagai media pembelajaran secara interaktif atau yang lainnya.

Kedua, penelitian pengembangan pembelajaran berbentuk multimedia berbasis video flash menggunakan aplikasi CS6 secara total tanpa menggunakan aplikasi pendukung yang lain. Dalam penelitian ini, pembuatan animasi yang digunakan aplikasi CS6 yang dikonversi secara langsung ke dalam video flash.

Ketiga, penelitian pengembangan media lainnya adalah pengembangan media pembelajaran teks anekdot berbasis animasi. Dalam penelitian menggunakan bentuk animasi PowToon. PowToon merupakan sebuah web service yang bisa digunakan untuk presentasi dengan rasa animasi. Melalui animasi PowToon tersebut akan menyesuaikan dengan materi yang akan digunakan.

Sedangkan pada pengembangan produk pictures movement ini mempunyai bentuk yang berbeda dengan animasi pada umumnya, dari perbedaan itulah media ini mempunyai karakteristik dari animasi yang sudah diteliti yang dipaparkan dalam kajian pustaka. 
Produk tersebut mempunyai karakteristik yaitu fleksibel dan variatif. Fleksibel diartikan bahwa fitur-fitur dalam menu bar yang bisa diganti sesuai dengan materi yang akan diajarkan karena produk ini dibuat secara manual. Karakteristik lain dari produk ini adalah dapat menampilkan produk dalam desain yang bervariasi, sehingga membuat siswa tidak bosan untuk melihat satu gambar yang hanya diam.

Berdasarkan pemaparan, maka dalam masalah materi paragraf berdasarkan kalimat utama (deduktif, induktif, campuran, dan ineratif) akan dikembangkan berupa media yaitu pictures movement yang nantinya diharapkan akan membantu memberikan inovasi dan kemudahan serta penyerapan materi kepada peserta didik dengan efektif dan efisien. Hal inilah yang melatarbelakangi diadakan penelitian guna mengembangkan media dalam menulis paragraf, sehingga penelitian ini berjudul "Pengembangan media pictures movement untuk pembelajaran menulis paragraf siswa kelas XII SMA." Permasalahan yang diajukan adalah efektivitas media pictures movement untuk pembelajaran menulis paragraf siswa kelas XII SMA.

METODE

Penelitian ini merupakan penelitian pengembangan atau Research \& Development (R\&D). Penelitian pengembangan adalah rangkaian proses atau langkah-langkah dalam rangka mengembangkan suatu produk baru atau memperbaiki produkproduk yang telah ada agar dapat dipertanggungjawabkan (Direktorat Tenaga Kependidikan dan Direktorat Jederal Peningkatan Mutu Pendidikan dan Tenaga Kependidikan dalam I Made Tegeh, dkk (2014: XIII). Tujuan penelitian pengembangan bukan untuk memformulasi atau menguji hipotesis, melainkan untuk mendapatkan produk baru atau proses baru. Penelitian ini mengembangkan produk berupa media pictures movement untuk pembelajaran menulis paragraf siswa kelas XII SMA.

Sugiono (2015:32-33) secara metodologis, penelitian pengembangan mempunyai empat tingkat kesulitan yaitu: meneliti tanpa menguji (tidak membuat dan tidak menguji produk), menguji tanpa meneliti (menguji validitas produk yang telah ada), meneliti dan menguji dalam upaya mengembangkan produk yang telah ada, dan meneliti dan menguji dalam menciptakan produk baru. Sedangkan dalam penelitian ini berada pada level keempat yaitu meneliti dan menguji dalam menciptakan produk baru. Untuk Pengumpulan Data pada Penelitian dan Pengembangan Level 4 (Meneliti \& Menguji dalam Menciptakan Produk Baru) dengan penjelasan sebagai berikut. 


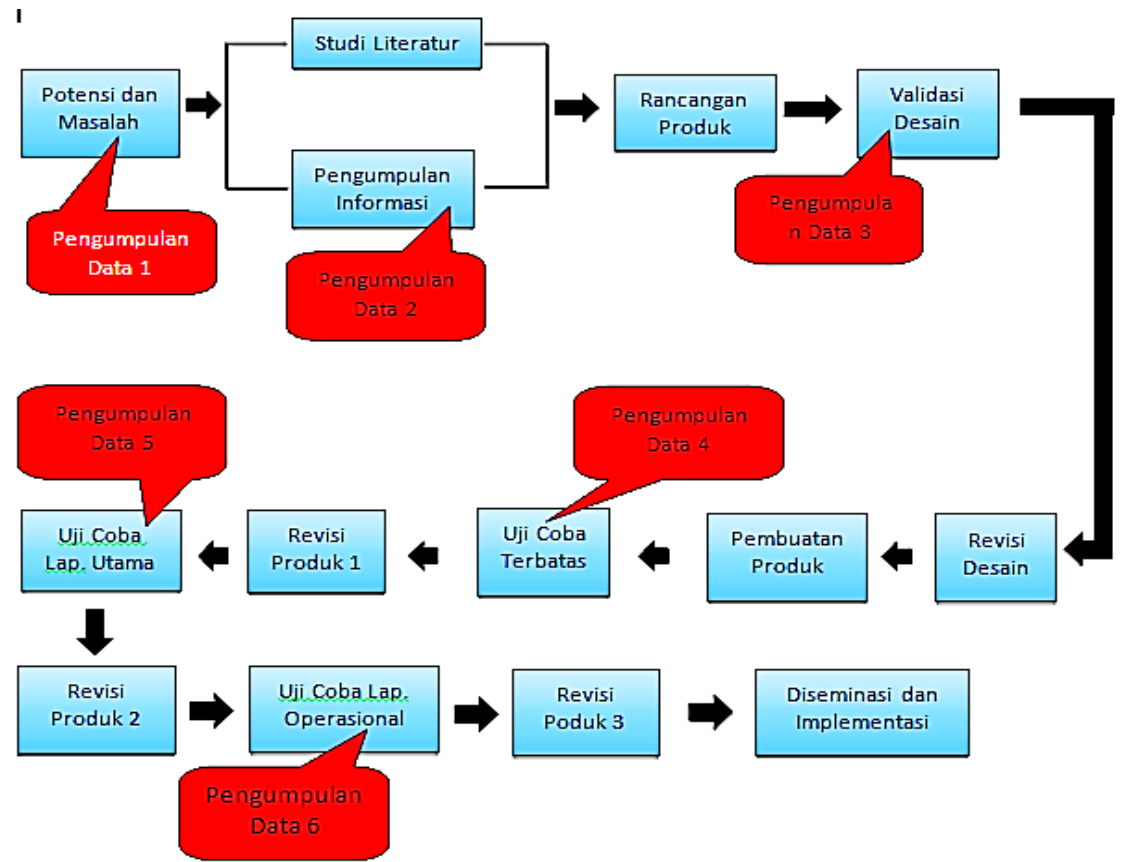

Rangkaian struktur pengumpulan data dari level 4 ini yaitu mulai dari potensi dan masalah (pengumpulan data 1), studi literartur/pengumpulan informasi (pengumpulan data 2), rancangan produk, validasi desain (pengumpulan data 3), revisi desain, dan pembuatan produk merupakan deskripsi untuk melihat proses pengembangan media pictures movement untuk pembelajaran menulis paragraf siswa kelas XII SMA Islam Miftahul Ulum. Sedangkan untuk uji coba terbatas (pengumpulan data 4), revisi produk, uji coba lapangan utama (pengumpulan data 5), dan revisi produk 2 merupakan deskripsi untuk melihat efektivitas media pictures movement untuk pembelajaran menulis paragraf siswa kelas XII SMA Islam Miftahul Ulum yang dikembangkan, dan yang terakhir adalah uji coba lapangan operasional (pengumpulan data 6), revisi produk 3 serta deseminasi dan implementasi merupakan deskripsi untuk melihat kepraktisan media pictures movement untuk pembelajaran menulis paragraf siswa kelas XII SMA Islam Miftahul Ulum yang dikembangkan.

Subjek pada tahap uji coba dalam penelitian ini adalah siswa kelas XII SMA Islam Miftahul Ulum dan guru Bahasa Indonesia sebagai pengguna media, sedangkan subjek pengembangan media ini adalah validator yaitu ahli media, ahli materi (expert) dan pengguna (user). Untuk data yang digunakan dalam penelitian pengembangan ini menggunakan data kualitatif. Data kualitatif merupakan data informasi yang berupa kalimat verbal bukan berupa simbol angka atau bilangan. Sedangkan untuk teknik pengumpulan data berupa wawancara, angket, dan tes. Pengumpulan data-data yang diperoleh dalam pengembangan produk ini melalui instrumen yaitu instrumen lembar wawancara, instrumen angket dan instrumen tes. Penelitian ini menggunakan analisis data deskriptif dengan satu variabel yaitu media pictures movement dengan materi menulis paragraf untuk siswa SMA kelas XII berdasarkan kriteria 
sumber belajar bentuk pictures movement yang baik yang telah diturunkan dalam kisi-kisi penilaian. Menurut (Sulaiman, 2015) analisis data deskriptif merupakan teknik analisis yang dipakai untuk menganalisis data dengan mendeskripsikan atau menggambarkan data-data yang sudah dikumpulkan seadanya tanpa ada maksud membuat generalisasi dari hasil penelitian.

Teknik pengumpulan data yang digunakan dalam uji coba produk adalah menggunakan uji validasi. Lembar validasi yang berupa instrumen validasi yang bertujuan untuk me-review dan responden. Seluruh hasil revisi yang berupa masukan terhadap media melalui instrumen validasi tersebut akan digunakan untuk dilakukan perbaikan terhadap produk yang akan dikembangkan yang di dalamnya memuat aspek-aspek penilaian, yaitu : (1) ahli media berupa : tampilan, kualitas teknis, konten, (2) ahli materi berupa : kualitas isi, instruksional, dan kebahasaan, (3) pengguna berupa : kualitas isi, instruksional, dan kebahasaan.

\section{PEMBAHASAN}

Penelitian ini bertujuan untuk mengembangkan media pembelajaran pictures movement yaitu sebuah media yang membantu siswa dalam pembelajaran menulis paragraf. Pembahasan hasil pengembangan media ini menekankan pada poinpoin permasalahan yang telah dipaparkan pada rumusan masalah yang menjadi proses uji coba produk, sehingga produk/media tersebut layak untuk digunakan dan berikut akan disajikan satu persatu hasil pengembangan dengan melihat pada data yang telah diperoleh.

\section{Proses Pengembangan Media Pictures Movement}

Berikut disajikan data hasil validasi oleh ahli media yang melakukan dua kali tahapan, ahli materi, serta pengguna media (guru bahasa Indonesia) yang hanya melakukan satu kali tahapan.

Tabel 1. Hasil Validasi Ahli Media, Ahli Materi, dan Pengguna (Guru Bahasa Indonesia) pada Keseluruhan Aspek.

\begin{tabular}{|c|c|c|c|c|c|c|c|}
\hline \multirow{2}{*}{ No. } & \multirow{2}{*}{ Pengujian } & \multicolumn{2}{|c|}{$\begin{array}{c}\text { Skor } \\
\text { rata-rata }\end{array}$} & \multicolumn{2}{c|}{ Persentase } & \multicolumn{2}{c|}{ Kategori } \\
\cline { 3 - 8 } & & I & II & I & II & I & II \\
\hline 1 & Ahli Media & 4.00 & 4.15 & $9.23 \%$ & $9.57 \%$ & Baik & Baik \\
\hline 2 & Ahli Materi & 4.22 & - & $11.50 \%$ & - & $\begin{array}{c}\text { Sangat } \\
\text { Baik }\end{array}$ & - \\
\hline 3 & Pengguna & 4.16 & 4.06 & $11.36 \%$ & $11.07 \%$ & Baik & Baik \\
\hline
\end{tabular}

Dari tabel tersebut dapat diketahui hasil dari ketiga aspek yaitu aspek tampilan, kualitas teknis, dan konten. Untuk ahli media 1 yaitu 4.00 dengan kategori "Baik", dan untuk ahli media 2 yaitu 4.15 dengan kategori "Baik". Sedangkan untuk ahli materi mendapatkan skor rata-rata 4.22 dengan kategori "Sangat Baik" dan yang terakhir untuk pengguna, hasil skor yang diperoleh (pengguna) guru 1 memperoleh skor rata-rata 4.16 dengan kategori 
"Baik", sedangkan skor yang diperoleh dari (pengguna) guru 2 yaitu memperoleh skor rata-rata 4.06 yang berkategori "Baik".

\section{Efektifitas Media Pictures Movement}

Setelah produk selesai dibuat, selanjutnya adalah tahap uji coba terbatas atau skala kecil yang berjumlah 5 orang siswa kelas XII SMA Islam Miftahul Ulum. Berikut hasil uji coba terbatas siswa.

Tabel 2. Data Hasil Uji Coba Terbatas Siswa (Skala Kecil).

\begin{tabular}{|c|c|c|c|c|c|}
\hline \multirow{2}{*}{ No. } & \multirow{2}{*}{ Nama } & \multicolumn{4}{|c|}{ Indikator Penilaian } \\
\hline & & Proses & Kesatuan & Koherensi & Kelengkapan \\
\hline 1. & $\begin{array}{l}\text { Amalia Farah } \\
\text { Diana }\end{array}$ & 4 & 4 & 2 & 3 \\
\hline 2. & Moh. Suhli & 4 & 4 & 2 & 4 \\
\hline 3. & $\begin{array}{l}\text { Asnaniyatur } \\
\text { Rahmah }\end{array}$ & 4 & 4 & 2 & 3 \\
\hline 4. & Ika Nurjanah & 4 & 3 & 1 & 3 \\
\hline 5. & $\begin{array}{l}\text { Faizatun } \\
\text { Musayyidah }\end{array}$ & 4 & 4 & 3 & 4 \\
\hline & Jumlah & 20 & 19 & 10 & 17 \\
\hline & kor Rata-rata & 4.00 & 3.80 & 2.00 & 3.40 \\
\hline & Persentase & $100 \%$ & $95.00 \%$ & $66.66 \%$ & $85.00 \%$ \\
\hline & Kategori & $\begin{array}{c}\text { Sangat } \\
\text { Baik }\end{array}$ & $\begin{array}{c}\text { Sangat } \\
\text { Baik }\end{array}$ & Baik & Sangat Baik \\
\hline
\end{tabular}

Berdasarkan tabel hasil uji coba terbatas (skala kecil) yang diikuti oleh 5 orang siswa di atas, dapat diketahui bahwa 4 indikator penilaian yang menjadi kriteria ketercapaian siswa memperoleh skor yang beragam. Untuk indikator penilaian pada "Proses" memperoleh skor rata-rata 4.00 dengan kategori "Sangat Baik". Sedangkan untuk indikator penilaian pada "Kesatuan" memperoleh skor rata-rata 3.80 memperoleh kategori "Sangat Baik". Selanjutnya indikator penilaian pada "Koherensi" memperoleh skor rata-rata 2.00 memperoleh kategori "Baik", dan yang terakhir indikator penilaian pada "Kelengkapan" memperoleh skor rata-rata 3.40 memperoleh kategori "Sangat Baik".

Tahapan berikutnya adalah uji coba lapangan utama (main field testing). Hasil uji coba lapangan utama ini juga untuk melihat keefektifan produk pada skala yang lebih besar/luas yaitu dengan jumlah 20 orang siswa kelas XII SMA Islam Miftahul Ulum. Berikut hasil uji coba lapangan utama siswa.

Tabel 3. Data Hasil Uji Coba Lapangan Utama (Main Field Testing)

\begin{tabular}{|c|c|c|c|c|c|}
\hline \multirow{2}{*}{ No. } & \multirow{2}{*}{ Nama } & \multicolumn{4}{|c|}{ Indikator Penilaian } \\
\cline { 3 - 6 } & & Proses & Kesatuan & Koherensi & Kelengkapan \\
\hline 1. & Responden A & 4 & 4 & 4 & 3 \\
\hline 2. & Responden B & 4 & 3 & 4 & 4 \\
\hline
\end{tabular}




\begin{tabular}{|c|c|c|c|c|c|}
\hline \multirow{2}{*}{ No. } & \multirow{2}{*}{ Nama } & \multicolumn{4}{|c|}{ Indikator Penilaian } \\
\hline & & Proses & Kesatuan & Koherensi & Kelengkapan \\
\hline 3. & Responden $\mathrm{C}$ & 4 & 4 & 4 & \begin{tabular}{|l|}
4 \\
\end{tabular} \\
\hline 4. & Responden D & 4 & 3 & 3 & 2 \\
\hline 5. & Responden E & 4 & 4 & 4 & 4 \\
\hline 6. & Responden F & 4 & 4 & 3 & 4 \\
\hline 7. & Responden G & 4 & 4 & 4 & 4 \\
\hline 8. & Responden $\mathrm{H}$ & 4 & 4 & 4 & 3 \\
\hline 9. & Responden I & 3 & 3 & 3 & 2 \\
\hline 10. & Responden J & 4 & 4 & 4 & 4 \\
\hline 11. & Responden K & 3 & 2 & 3 & 3 \\
\hline 12. & Responden L & 4 & 4 & 4 & 4 \\
\hline 13. & Responden M & 4 & 3 & 3 & 3 \\
\hline 14. & Responden N & 4 & 4 & 4 & 4 \\
\hline 15. & Responden $\mathrm{O}$ & 4 & 3 & 3 & 2 \\
\hline 16. & Responden P & 4 & 4 & 4 & 4 \\
\hline 17. & Responden Q & 4 & 4 & 3 & 4 \\
\hline 18. & Responden R & 4 & 3 & 3 & 3 \\
\hline 19. & Responden S & 4 & 4 & 3 & 4 \\
\hline 20. & Responden T & 4 & 3 & 3 & 2 \\
\hline & Jumlah & 78 & 71 & 70 & 67 \\
\hline & or Rata-rata & 3.90 & 3.55 & 3.50 & 3.35 \\
\hline & Persentase & $97.50 \%$ & $88.75 \%$ & $87.50 \%$ & $83.75 \%$ \\
\hline & Kategori & $\begin{array}{c}\text { Sangat } \\
\text { Baik }\end{array}$ & $\begin{array}{c}\text { Sangat } \\
\text { Baik }\end{array}$ & $\begin{array}{c}\text { Sangat } \\
\text { Baik }\end{array}$ & $\begin{array}{c}\text { Sangat } \\
\text { Baik }\end{array}$ \\
\hline
\end{tabular}

Berdasarkan tabel hasil uji coba lapangan utama (skala besar) yang diikuti oleh 20 orang siswa di atas, dapat diketahui bahwa 4 indikator penilaian yang menjadi kriteria ketercapaian siswa memperoleh skor yang variatif. Untuk indikator penilaian pada "proses" memperoleh skor rata-rata 3.90 dengan kategori "Sangat Baik". Sedangkan untuk indikator penilaian pada "kesatuan" memperoleh skor rata-rata 3.55 memperoleh kategori "Sangat Baik". Selanjutnya indikator penilaian pada "koherensi" memperoleh skor rata-rata 3.50 memperoleh kategori "Sangat Baik", dan yang terakhir indikator penilaian pada "kelengkapan" memperoleh skor rata-rata 3.35 memperoleh kategori "Sangat Baik".

\section{Kepraktisan Media Pictures Movement}

Uji coba lapangan operasional dilakukan untuk mengetahui kepraktisan dari media/produk pictures movement dengan menggunakan instrument wawancara dan angket respon siswa. Instrument wawancara akan diisi oleh guru yang sudah melakukan pembelajaran pada proses penelitian dengan menggunakan media pictures movement yang dimulai dari penelitian uji coba terbatas dan uji coba lapangan utama. Berikut hasil wawancara peneliti dengan guru bahasa Indonesia. 
Tabel 4. Data Hasil Wawancara Guru

\begin{tabular}{|c|c|c|}
\hline No & Pertanyaan & Jawaban \\
\hline 1. & $\begin{array}{l}\text { Menurut Ibu, bagaimana } \\
\text { setelah melakukan } \\
\text { pembelajaran dengan } \\
\text { menggunakan media } \\
\text { pictures movement? }\end{array}$ & $\begin{array}{l}\text { Sangat terbantu sekali dalam } \\
\text { pembelajaran karena media } \\
\text { pictures movement ini sangat } \\
\text { efektif dan efisien. }\end{array}$ \\
\hline 2. & $\begin{array}{l}\text { Apakah ada perkembangan } \\
\text { yang signifikan dalam } \\
\text { menulis paragraf siswa? }\end{array}$ & $\begin{array}{l}\text { Kalau dibandingkan dengan } \\
\text { pembelajaran sebelumnya tentu } \\
\text { ada. }\end{array}$ \\
\hline 3. & $\begin{array}{l}\text { Menurut Ibu, } \\
\text { perkembangan seperti apa } \\
\text { yang telah diperoleh siswa } \\
\text { dalam pembelajaran } \\
\text { menulis paragraf? }\end{array}$ & $\begin{array}{l}\text { Perkembangan yang diperoleh } \\
\text { siswa dalam menulis paragraf } \\
\text { dengan menggunakan media } \\
\text { pictures movement ini adalah tentu } \\
\text { lebih gampang dalam menyerap } \\
\text { pembelajaran, lebih banyak ide } \\
\text { yang didapat siswa melalui } \\
\text { animasi, cepat tanggap, lebih cepat } \\
\text { dalam menulis paragraf karena } \\
\text { terbantu dengan contoh yang } \\
\text { dinamis. }\end{array}$ \\
\hline 4. & $\begin{array}{l}\text { Dalam pembelajaran } \\
\text { menulis paragraf, apakah } \\
\text { Ibu terbantu dengan media } \\
\text { pembelajaran pictures } \\
\text { movement? }\end{array}$ & $\begin{array}{l}\text { Sangat terbantu sekali dengan } \\
\text { terciptanya media pictures } \\
\text { movement ini karena membuat } \\
\text { pembelajaran tidak monoton dan } \\
\text { lebih variatif, sehingga siswa } \\
\text { merasa senang. }\end{array}$ \\
\hline 5. & $\begin{array}{l}\text { Apakah media } \\
\text { pembelajaran pictures } \\
\text { movement telah menjawab } \\
\text { permasalahan yang } \\
\text { signifikan dalam } \\
\text { pembelajaran menulis } \\
\text { paragraf? }\end{array}$ & $\begin{array}{l}\text { Secara teori dan praktik memang } \\
\text { sudah terjawab karena media ini } \\
\text { benar-benar membantu terhadap } \\
\text { pembelajaran, apalagi pada ranah } \\
\text { kognitif seperti halnya menulis. }\end{array}$ \\
\hline 6. & $\begin{array}{l}\text { Bagaimana prestasi belajar } \\
\text { siswa dalam menulis } \\
\text { paragraf setelah } \\
\text { diterapkannya media } \\
\text { pictures movement? }\end{array}$ & $\begin{array}{l}\text { Sejauh ini sudah menampakkan } \\
\text { atau sudah terlihat hasil } \\
\text { keefektifan dari media ini. } \\
\text { Terbukti dari hasil pembelajaran } \\
\text { yang sudah dilakukan. }\end{array}$ \\
\hline 7. & $\begin{array}{l}\text { Menurut Ibu, berapakah } \\
\text { rata-rata siswa yang } \\
\text { berhasil atau terbantu dalam } \\
\text { menulis paragraf dengan } \\
\text { menggunakan media } \\
\text { pembelajaran pictures } \\
\text { movement ini? }\end{array}$ & $\begin{array}{l}\text { Dari jumlah keseluruhan siswa } \\
\text { yaitu } 20 \text { orang siswa, rata-rata } \\
\text { yang terbantu dalam menulis } \\
\text { paragraf dengan menggunakan } \\
\text { media pictures movement adalah } \\
17 \text { orang siswa. }\end{array}$ \\
\hline 8. & $\begin{array}{l}\text { Berapa persen (\%) media } \\
\text { pembelajaran pictures } \\
\text { movement membantu } \\
\text { prestasi belajar siswa dalam } \\
\text { menulis paragraf? }\end{array}$ & $\begin{array}{l}\text { Dari pembelajaran yang sudah } \\
\text { dilakukan, kurang lebih } 87 \% \\
\text { keefektifan media ini bisa terserap } \\
\text { oleh siswa dalam prestasi belajar } \\
\text { menulis paragraf. }\end{array}$ \\
\hline
\end{tabular}




\begin{tabular}{|c|l|l|}
\hline No & \multicolumn{1}{|c|}{ Pertanyaan } & \multicolumn{1}{c|}{ Jawaban } \\
\hline 9. & $\begin{array}{l}\text { Apakah media pictures } \\
\text { movement yang digunakan } \\
\text { Ibu dalam pembelajaran } \\
\text { menulis paragraf masih } \\
\text { terdapat kekurangan } \\
\text { sehingga harus diperbaiki }\end{array}$ & $\begin{array}{l}\text { Apapun media yang digunakan } \\
\text { sebagai alat pembelajaran tentu } \\
\text { mempunyai kekurangan, begitupun } \\
\text { dengan media pictures movement } \\
\text { ini. Kekurangan dari media ini } \\
\text { adalah konversi videonya harus } \\
\text { diganti agar bisa dilakukan pause } \\
\text { sehingga siswa bisa mengontrol } \\
\text { dengan sendirinya apabila masih } \\
\text { kurang paham. }\end{array}$ \\
\hline 10. & $\begin{array}{l}\text { Saya kira media ini akan } \\
\text { mempunyai prospek yang bagus } \\
\text { media pembelajaran } \\
\text { untuk pembelajaran menulis } \\
\text { pictures movement, apakah } \\
\text { pengembangan media ini } \\
\text { akan mempunyai prospek } \\
\text { yang bagus di dalam } \\
\text { menulis paragraf ? }\end{array}$ & $\begin{array}{l}\text { meningkatkan kualitas menulis } \\
\text { siswa. Selain itu karena sifatnya } \\
\text { yang dinamis, jadi bisa } \\
\text { menyesuaikan dengan materi yang } \\
\text { akan diberikan kepada siswa. }\end{array}$ \\
\hline
\end{tabular}

Berdasarkan dari data hasil wawancara yang dilakukan oleh peneliti kepada guru Bahasa Indonesia dapat disimpulkan bahwa guru tersebut merasa terbantu dalam pemberian materi menulis paragraf kepada siswa karena media pictures movement ini adalah media elektronik yang fleksibel dan variatif sehingga pembelajaran tidak monoton dan tercipta kelas yang kondusif, menyenangkan serta praktis.

Sedangkan untuk angket akan diisi oleh siswa SMA Islam Miftahul Ulum kelas XII yang sudah mengikuti dan melakukan serangkaian pembelajaran dalam menulis paragraf pada proses penelitian dengan menggunakan media pictures movement yang dimulai dari penelitian uji coba terbatas dan uji coba lapangan utama. Berikut hasil angket respon siswa.

Tabel. 5 Data Hasil Angket Respon Siswa

\begin{tabular}{|c|c|c|c|c|c|c|c|c|c|c|c|c|c|c|c|c|c|c|c|c|c|c|}
\hline \multirow{2}{*}{ No } & \multirow{2}{*}{ Pernyataan } & \multirow{2}{*}{ 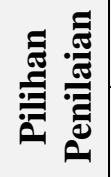 } & \multicolumn{20}{|c|}{ Responden } \\
\hline & & & 1 & 2 & 3 & 4 & 5 & 6 & 7 & 8 & 9 & 0 & $|1| 1$ & & \begin{tabular}{l|l|}
13 & 1
\end{tabular} & 14 & & 161 & 171 & 181 & & 20 \\
\hline \multirow{5}{*}{1} & \multirow{5}{*}{$\begin{array}{l}\text { Tampilan } \\
\text { media } \\
\text { pembelajaran } \\
\text { menarik. }\end{array}$} & SS & $\sqrt{ }$ & & & $\sqrt{ }$ & $\sqrt{1}$ & $\sqrt{ }$ & & $\sqrt{ }$ & & & $\sqrt{ }$ & $\sqrt{ }$ & & & & $\sqrt{ }$ & & & & \\
\hline & & ST & & $\sqrt{ }$ & $\sqrt{ }$ & & & & $\sqrt{1}$ & & $\sqrt{1}$ & $\sqrt{ }$ & & & $\sqrt{ }$ & $\sqrt{ }$ & $\sqrt{ }$ & & $\sqrt{ }$ & $\sqrt{ }$ & $\sqrt{ }$ & $\sqrt{ }$ \\
\hline & & RG & & & & & & & & & & & & & & & & & & & & \\
\hline & & TS & & & & & & & & & & & & & & & & & & & & \\
\hline & & STS & & & & & & & & & & & & & & & & & & & & \\
\hline \multirow{3}{*}{2} & \multirow{3}{*}{$\begin{array}{l}\text { Penggunaan } \\
\text { media } \\
\text { pembelajaran } \\
\text { mempermudah } \\
\text { siswa dalam } \\
\text { proses }\end{array}$} & SS & $\sqrt{ }$ & & $\sqrt{ }$ & & & $\sqrt{ }$ & & $\sqrt{ }$ & & & & & & & & $\sqrt{ }$ & & & $\sqrt{ }$ & \\
\hline & & ST & & $\sqrt{ }$ & & $\sqrt{ }$ & $\sqrt{ }$ & & $\sqrt{ }$ & & $\sqrt{ }$ & $\sqrt{ }$ & $\sqrt{ }$ & & $\sqrt{ }$ & & & & $\sqrt{ }$ & $\sqrt{ }$ & & $\sqrt{ }$ \\
\hline & & RG & & & & & & & & & & & & $\sqrt{ }$ & & $\sqrt{ }$ & $\sqrt{ }$ & & & & & \\
\hline
\end{tabular}




\begin{tabular}{|c|c|c|c|c|c|c|c|c|c|c|c|c|c|c|c|c|c|c|c|c|c|}
\hline \multirow{4}{*}{ No } & \multirow{2}{*}{ Pernyataan } & \multirow{2}{*}{ 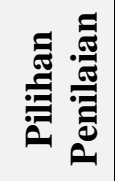 } & \multicolumn{19}{|c|}{ Responden } \\
\hline & & & 1 & 2 & 3 & 4 & 5 & 6 & 7 & 8 & 9 & 101 & & & $\begin{array}{ll}3 & 1\end{array}$ & 41 & 51 & 17 & 18 & 19 & 20 \\
\hline & penyerapan & TS & & & & & & & & & & & & & & & & & & & \\
\hline & pembelajaran. & STS & & & & & & & & & & & & & & & & & & & \\
\hline \multirow{5}{*}{3} & \multirow{5}{*}{$\begin{array}{l}\text { Jenis tulisan } \\
\text { yang } \\
\text { digunakan } \\
\text { pada media } \\
\text { pembelajaran } \\
\text { mudah dibaca } \\
\text { dan jelas. }\end{array}$} & SS & $\sqrt{ }$ & & & $\sqrt{ }$ & & $\sqrt{ }$ & & $\sqrt{ }$ & & & $\sqrt{ }$ & $\sqrt{ }$ & & 1) & 1 & & $\sqrt{ }$ & & \\
\hline & & ST & & $\sqrt{ }$ & $\sqrt{ }$ & & $\sqrt{ }$ & & $\sqrt{ }$ & & $\sqrt{ }$ & $\sqrt{ }$ & & & $\sqrt{ }$ & & & $v$ & & $\sqrt{ }$ & $\sqrt{ }$ \\
\hline & & RG & & & & & & & & & & & & & & & & & & & \\
\hline & & TS & & & & & & & & & & & & & & & & & & & \\
\hline & & STS & & & & & & & & & & & & & & & & & & & \\
\hline \multirow{5}{*}{4} & \multirow{5}{*}{$\begin{array}{l}\text { Penggunaan } \\
\text { bahasa yang } \\
\text { terdapat pada } \\
\text { media } \\
\text { pembelajaran } \\
\text { mudah } \\
\text { dipahami. }\end{array}$} & SS & & & $\sqrt{ }$ & & & $\sqrt{ }$ & & $\sqrt{ }$ & & & $\sqrt{ }$ & & $\sqrt{ }$ & & 1 & & $\sqrt{ }$ & & \\
\hline & & ST & $\sqrt{ }$ & $\sqrt{ }$ & & $\sqrt{ }$ & $\sqrt{ }$ & & $\sqrt{ }$ & & $\sqrt{ }$ & $\sqrt{ }$ & & & & 1 & & 1 & & $\sqrt{ }$ & $\sqrt{ }$ \\
\hline & & RG & & & & & & & & & & & & $\sqrt{ }$ & & & & & & & \\
\hline & & TS & & & & & & & & & & & & & & & & & & & \\
\hline & & STS & & & & & & & & & & & & & & & & & & & \\
\hline \multirow{5}{*}{5} & \multirow{5}{*}{$\begin{array}{l}\text { Tampilan } \\
\text { media } \\
\text { pembelajaran } \\
\text { mudah } \\
\text { dipahami } \\
\text { dengan jelas } \\
\text { sehingga tidak } \\
\text { menimbulkan } \\
\text { kebingungan } \\
\text { dan } \\
\text { keambiguan. }\end{array}$} & SS & & & & & & & $\sqrt{ }$ & $\sqrt{ }$ & & & & & & & & 1 & & $\sqrt{ }$ & \\
\hline & & ST & $\sqrt{ }$ & $\sqrt{ }$ & $\sqrt{ }$ & $\sqrt{ }$ & $\sqrt{ }$ & $\sqrt{ }$ & & & $\sqrt{ }$ & $\sqrt{ }$ & $\sqrt{ }$ & & $\sqrt{ }$ & 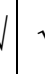 & 1 & & $\sqrt{ }$ & & $\sqrt{ }$ \\
\hline & & RG & & & & & & & & & & & & $\sqrt{ }$ & & & & & & & \\
\hline & & TS & & & & & & & & & & & & & & & & & & & \\
\hline & & STS & & & & & & & & & & & & & & & & & & & \\
\hline \multirow{5}{*}{6} & \multirow{5}{*}{$\begin{array}{l}\text { Kesesuaian } \\
\text { warna yang } \\
\text { terdapat pada } \\
\text { masing-masing } \\
\text { objek pada } \\
\text { media } \\
\text { pembelajaran } \\
\text { sesuai. }\end{array}$} & SS & $\sqrt{ }$ & & & $\sqrt{ }$ & & & & & & & $\sqrt{ }$ & $\sqrt{ }$ & & & 1 & & & & \\
\hline & & ST & & & $\sqrt{ }$ & & $\sqrt{ }$ & $\sqrt{ }$ & $\sqrt{ }$ & $\sqrt{ }$ & & $\sqrt{ }$ & & & $\sqrt{ }$ & 1 & & $v$ & $\sqrt{ }$ & $\sqrt{ }$ & $\sqrt{ }$ \\
\hline & & RG & & $\sqrt{ }$ & & & & & & & $\sqrt{ }$ & & & & & & & & & & \\
\hline & & TS & & & & & & & & & & & & & & & & & & & \\
\hline & & STS & & & & & & & & & & & & & & & & & & & \\
\hline \multirow{4}{*}{7} & \multirow{4}{*}{$\begin{array}{l}\text { Pictures } \\
\text { movement pada } \\
\text { media } \\
\text { pembelajaran } \\
\text { tidak } \\
\text { mengganggu } \\
\text { konsentrasi } \\
\text { siswa saat }\end{array}$} & SS & & & $\sqrt{ }$ & & $\sqrt{ }$ & & & $\sqrt{ }$ & & & $\sqrt{ }$ & & $\sqrt{ }$ & & & 1 & & $\sqrt{ }$ & \\
\hline & & ST & $\sqrt{ }$ & & & $\sqrt{ }$ & & $\sqrt{ }$ & $\sqrt{ }$ & & & $\sqrt{ }$ & & & & & 1 & & $\sqrt{ }$ & & \\
\hline & & RG & & $\sqrt{ }$ & & & & & & & $\sqrt{ }$ & & & & & 1 & & & & & $\sqrt{ }$ \\
\hline & & TS & & & & & & & & & & & & $\sqrt{ }$ & & & & & & & \\
\hline
\end{tabular}




\begin{tabular}{|c|c|c|c|c|c|c|c|c|c|c|c|c|c|c|c|c|c|c|c|c|c|c|c|}
\hline \multirow{3}{*}{ No } & & $\Xi$. & \multicolumn{21}{|c|}{ Responden } \\
\hline & & $=$ & 1 & 2 & 3 & 4 & 5 & c & ' & & 8 & 9 & 10 & 11 & 12 & 13 & & 15 & 16 & $17 \mid$. & 18 & & 20 \\
\hline & belajar. & STS & & & & & & & & & & & & & & & & & & & & & \\
\hline \multirow{5}{*}{8} & \multirow{5}{*}{$\begin{array}{l}\text { Sistematika } \\
\text { penyajian } \\
\text { materi pada } \\
\text { media } \\
\text { pembelajaran } \\
\text { mudah } \\
\text { dipahami oleh } \\
\text { siswa. }\end{array}$} & SS & $\sqrt{ }$ & & $\sqrt{ }$ & $V$ & & 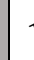 & & & & & & & & & & & $\sqrt{ }$ & & & & \\
\hline & & ST & & $\sqrt{ }$ & & & 1 & & & $\sqrt{ }$ & $\sqrt{ }$ & $\sqrt{ }$ & $\sqrt{ }$ & $\sqrt{ }$ & $\sqrt{ }$ & $\sqrt{ }$ & $\sqrt{ }$ & & & $\sqrt{ }$ & $\sqrt{ }$ & $\sqrt{ }$ & $\sqrt{ }$ \\
\hline & & RG & & & & & & & & & & & & & & & & $\sqrt{ }$ & & & & & \\
\hline & & TS & & & & & & & & & & & & & & & & & & & & & \\
\hline & & STS & & & & & & & & & & & & & & & & & & & & & \\
\hline \multirow{5}{*}{9} & \multirow{5}{*}{$\begin{array}{l}\text { Media } \\
\text { pembelajaran } \\
\text { pictures } \\
\text { movement } \\
\text { memberikan } \\
\text { kemudahan } \\
\text { kepada siswa } \\
\text { untuk } \\
\text { mengembangk } \\
\text { an } \\
\text { pembelajaran } \\
\text { menulis } \\
\text { paragraf } \\
\text { menjadi } \\
\text { sebuah } \\
\text { karangan. }\end{array}$} & SS & & & & & & & & & & & & $\sqrt{ }$ & & & $\sqrt{ }$ & & $\sqrt{ }$ & & & & \\
\hline & & ST & & $\sqrt{ }$ & $\sqrt{ }$ & v & l & 1 & & $\sqrt{ }$ & & $\sqrt{ }$ & & & & $\sqrt{ }$ & & $\sqrt{ }$ & & $\sqrt{ }$ & $\sqrt{ }$ & $\sqrt{ }$ & \\
\hline & & RG & $\sqrt{ }$ & & & & & & & & $\sqrt{ }$ & & $\sqrt{ }$ & & $\sqrt{ }$ & & & & & & & & $\sqrt{ }$ \\
\hline & & TS & & & & & & & & & & & & & & & & & & & & & \\
\hline & & STS & & & & & & & & & & & & & & & & & & & & & \\
\hline \multirow{5}{*}{10} & \multirow{5}{*}{$\begin{array}{l}\text { Media } \\
\text { pembelajaran } \\
\text { memberikan } \\
\text { kesempatan } \\
\text { kepada siswa } \\
\text { untuk latihan } \\
\text { lebih } \\
\text { mendalam } \\
\text { secara teori. }\end{array}$} & SS & $\sqrt{ }$ & $\sqrt{ }$ & $\sqrt{ }$ & $V$ & & & & & $\sqrt{ }$ & $\sqrt{ }$ & & & & & & & $\sqrt{ }$ & $\sqrt{ }$ & & & \\
\hline & & ST & & & & & r & & & $\sqrt{ }$ & & & $\sqrt{ }$ & $\sqrt{ }$ & $\sqrt{ }$ & $\sqrt{ }$ & $\sqrt{ }$ & & & & $\sqrt{ }$ & $\sqrt{ }$ & $\sqrt{ }$ \\
\hline & & RG & & & & & & & & & & & & & & & & $\sqrt{ }$ & & & & & \\
\hline & & TS & & & & & & & & & & & & & & & & & & & & & \\
\hline & & STS & & & & & & & & & & & & & & & & & & & & & \\
\hline \multirow{5}{*}{11} & \multirow{5}{*}{$\begin{array}{l}\text { Media } \\
\text { pembelajaran } \\
\text { mempunyai } \\
\text { sifat } \\
\text { multifungsi } \\
\text { sehingga dapat } \\
\text { digunakan } \\
\text { untuk } \\
\text { pembelajaran } \\
\text { di sekolah } \\
\text { maupun di } \\
\text { rumah secara } \\
\text { mandiri. }\end{array}$} & SS & $\sqrt{ }$ & & $\sqrt{ }$ & $\sqrt{ }$ & 1 & & & & $\sqrt{ }$ & & & & & $\sqrt{ }$ & & & $\sqrt{ }$ & & & & \\
\hline & & ST & & $\sqrt{ }$ & & & & & & $\sqrt{1}$ & & $\sqrt{ }$ & $\sqrt{ }$ & $\sqrt{ }$ & $\sqrt{ }$ & & $\sqrt{ }$ & $\sqrt{ }$ & & $\sqrt{ }$ & & $\sqrt{ }$ & \\
\hline & & RG & & & & & & & & & & & & & & & & & & & $\sqrt{ }$ & & $\sqrt{ }$ \\
\hline & & TS & & & & & & & & & & & & & & & & & & & & & \\
\hline & & STS & & & & & & & & & & & & & & & & & & & & & \\
\hline
\end{tabular}




\begin{tabular}{|c|c|c|c|c|c|c|c|c|c|c|c|c|c|c|c|c|c|c|c|c|c|c|c|}
\hline \multirow{2}{*}{ No } & \multirow{2}{*}{ Pernyataan } & \multirow{2}{*}{ 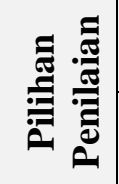 } & \multicolumn{21}{|c|}{ Responden } \\
\hline & & & 1 & 2 & 3 & 4 & 5 & & & 7 & 8 & 9 & 10 & 11 & 12 & 13 & 14 & 15 & 16 & 17 & 18 & 19 & 20 \\
\hline \multirow{5}{*}{12} & \multirow{5}{*}{$\begin{array}{l}\text { Contoh yang } \\
\text { diberikan pada } \\
\text { media } \\
\text { pembelajaran } \\
\text { relevan dengan } \\
\text { materi. }\end{array}$} & SS & $\sqrt{ }$ & & $\sqrt{ }$ & & & $\sqrt{ }$ & & & $\sqrt{ }$ & & & $\sqrt{ }$ & & $\sqrt{ }$ & $\sqrt{ }$ & & $\sqrt{ }$ & & $\sqrt{ }$ & & \\
\hline & & ST & & & & 1 & & & $\sqrt{ }$ & $\sqrt{ }$ & & & $\sqrt{ }$ & & $\sqrt{ }$ & & & $\sqrt{ }$ & & $\sqrt{ }$ & & $\sqrt{ }$ & $\sqrt{ }$ \\
\hline & & RG & & $\sqrt{ }$ & & & & & & & & $\sqrt{ }$ & & & & & & & & & & & \\
\hline & & TS & & & & & & & & & & & & & & & & & & & & & \\
\hline & & STS & & & & & & & & & & & & & & & & & & & & & \\
\hline \multirow{5}{*}{13} & \multirow{5}{*}{$\begin{array}{l}\text { Isi materi pada } \\
\text { media } \\
\text { pembelajaran } \\
\text { sesuai dengan } \\
\text { tujuan } \\
\text { pembelajaran. }\end{array}$} & SS & $\sqrt{ }$ & & $\sqrt{ }$ & 1 & & & & & $\sqrt{ }$ & & & $\sqrt{ }$ & & $\sqrt{ }$ & $\sqrt{ }$ & & $\sqrt{ }$ & & & & \\
\hline & & ST & & $\sqrt{ }$ & & & & & $\sqrt{ }$ & $\sqrt{ }$ & & $\sqrt{ }$ & $\sqrt{ }$ & & & & & $\sqrt{ }$ & & $\sqrt{ }$ & $\sqrt{ }$ & $\sqrt{ }$ & $\sqrt{ }$ \\
\hline & & RG & & & & & & & & & & & & & $\sqrt{ }$ & & & & & & & & \\
\hline & & TS & & & & & & & & & & & & & & & & & & & & & \\
\hline & & STS & & & & & & & & & & & & & & & & & & & & & \\
\hline \multirow{5}{*}{14} & \multirow{5}{*}{$\begin{array}{l}\text { Kualitas } \\
\text { gambar } \\
\text { Pictures } \\
\text { movement pada } \\
\text { media } \\
\text { pembelajaran } \\
\text { sangat jelas } \\
\text { dan bagus. }\end{array}$} & SS & $\sqrt{ }$ & $\sqrt{ }$ & & J & & & & & $\sqrt{ }$ & $\sqrt{ }$ & & & & $\sqrt{ }$ & $\sqrt{ }$ & & $\sqrt{ }$ & & & & \\
\hline & & ST & & & $\sqrt{ }$ & & & & $\sqrt{ }$ & $\sqrt{ }$ & & & & $\sqrt{ }$ & $\sqrt{ }$ & & & $\sqrt{ }$ & & $\sqrt{ }$ & $\sqrt{ }$ & $\sqrt{ }$ & $\sqrt{ }$ \\
\hline & & RG & & & & & & & & & & & $\sqrt{ }$ & & & & & & & & & & \\
\hline & & TS & & & & & & & & & & & & & & & & & & & & & \\
\hline & & STS & & & & & & & & & & & & & & & & & & & & & \\
\hline \multirow{5}{*}{15} & \multirow{5}{*}{\begin{tabular}{|l} 
Materi \\
pembelajaran \\
sesuai dengan \\
kompetensi \\
dasar yaitu \\
Menulis \\
karangan \\
berdasarkan \\
topik tertentu \\
dengan pola \\
pengembangan \\
deduktif dan \\
induktif. \\
\end{tabular}} & SS & & & & 1 & & & & & $\sqrt{ }$ & & & $\sqrt{ }$ & & & & & & & $\sqrt{ }$ & $\sqrt{ }$ & \\
\hline & & ST & $\sqrt{ }$ & $\sqrt{ }$ & $\sqrt{ }$ & & & & & $\sqrt{ }$ & & $\sqrt{ }$ & $\sqrt{ }$ & & $\sqrt{ }$ & $\sqrt{ }$ & $\sqrt{ }$ & $\sqrt{ }$ & $\sqrt{ }$ & $\sqrt{ }$ & & & $\sqrt{ }$ \\
\hline & & RG & & & & & & & & & & & & & & & & & & & & & \\
\hline & & TS & & & & & & & & & & & & & & & & & & & & & \\
\hline & & STS & & & & & & & & & & & & & & & & & & & & & \\
\hline \multirow{5}{*}{16} & \multirow{5}{*}{$\begin{array}{l}\text { Evaluasi pada } \\
\text { media } \\
\text { pembelajaran } \\
\text { relevan dengan } \\
\text { materi. }\end{array}$} & SS & & & $\sqrt{ }$ & & & & & & $\sqrt{ }$ & & & $\sqrt{ }$ & & & & & $\sqrt{ }$ & $\sqrt{ }$ & & & \\
\hline & & ST & $\sqrt{ }$ & $\sqrt{ }$ & & 1 & & & $\sqrt{ }$ & $\sqrt{ }$ & & $\sqrt{ }$ & $\sqrt{ }$ & & $\sqrt{ }$ & $\sqrt{ }$ & $\sqrt{ }$ & & & & $\sqrt{ }$ & $\sqrt{ }$ & $\sqrt{ }$ \\
\hline & & RG & & & & & & & & & & & & & & & & $\sqrt{ }$ & & & & & \\
\hline & & TS & & & & & & & & & & & & & & & & & & & & & \\
\hline & & STS & & & & & & & & & & & & & & & & & & & & & \\
\hline \multirow{5}{*}{17} & \multirow{5}{*}{$\begin{array}{l}\text { Animasi/pictur } \\
\text { e movement } \\
\text { pada media } \\
\text { pembelajaran } \\
\text { penting dalam } \\
\text { memperjelas } \\
\text { pemahaman } \\
\text { materi. }\end{array}$} & SS & $\sqrt{ }$ & & $\sqrt{ }$ & 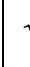 & & & $\sqrt{ }$ & & $\sqrt{ }$ & & & & & & & & & $\sqrt{ }$ & & $\sqrt{ }$ & \\
\hline & & ST & & $\sqrt{ }$ & & & & & & $\sqrt{ }$ & & $\sqrt{ }$ & $\sqrt{ }$ & $\sqrt{ }$ & $\sqrt{ }$ & $\sqrt{ }$ & $\sqrt{ }$ & & $\sqrt{ }$ & & $\sqrt{ }$ & & $\sqrt{ }$ \\
\hline & & RG & & & & & & & & & & & & & & & & $\sqrt{ }$ & & & & & \\
\hline & & TS & & & & & & & & & & & & & & & & & & & & & \\
\hline & & STS & & & & & & & & & & & & & & & & & & & & & \\
\hline 18 & Uraian materi & SS & $\sqrt{ }$ & & $\sqrt{ }$ & & & & & & $\sqrt{ }$ & & & & & $\sqrt{ }$ & & & & $\sqrt{1}$ & & & \\
\hline
\end{tabular}




\begin{tabular}{|c|c|c|c|c|c|c|c|c|c|c|c|c|c|c|c|c|c|c|c|c|c|c|}
\hline \multirow{6}{*}{ No } & \multirow{2}{*}{ Pernyataan } & \multirow{2}{*}{ 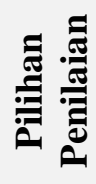 } & \multicolumn{20}{|c|}{ Responden } \\
\hline & & & 1 & 2 & 3 & 4 & 5 & 6 & 7 & 8 & 9 & 10 & 11 & 12 & $|3|$ & 141 & 151 & $16 \mid 1$ & $17 \mid 1$ & \begin{tabular}{l|l}
8 & 1
\end{tabular} & & 20 \\
\hline & \multirow{4}{*}{$\begin{array}{l}\text { pada media } \\
\text { pembelajaran } \\
\text { sudah lengkap. }\end{array}$} & ST & & $\sqrt{ }$ & & & $\sqrt{ }$ & $\sqrt{ }$ & $\sqrt{ }$ & & $\sqrt{ }$ & & $\sqrt{ }$ & $\sqrt{ }$ & & $\sqrt{ }$ & $\sqrt{ }$ & $\sqrt{ }$ & & $\sqrt{ }$ & $\sqrt{ }$ & \\
\hline & & RG & & & & & & & & & & $\sqrt{ }$ & & & & & & & & & & $\sqrt{ }$ \\
\hline & & TS & & & & & & & & & & & & & & & & & & & & \\
\hline & & STS & & & & & & & & & & & & & & & & & & & & \\
\hline \multirow{5}{*}{19} & \multirow{5}{*}{$\begin{array}{l}\text { Media } \\
\text { pembelajaran } \\
\text { dapat } \\
\text { memperjelas } \\
\text { penyajian } \\
\text { materi } \\
\text { sehingga dapat } \\
\text { meningkatkan } \\
\text { hasil belajar } \\
\text { siswa. }\end{array}$} & SS & $\sqrt{ }$ & & $\sqrt{ }$ & $\sqrt{ }$ & & & & & & & & & & & & $\sqrt{ }$ & & & & \\
\hline & & ST & & $\sqrt{ }$ & & & $\sqrt{ }$ & $\sqrt{ }$ & $\sqrt{ }$ & $\sqrt{ }$ & $\sqrt{ }$ & & $\sqrt{ }$ & & $\sqrt{ }$ & $\sqrt{ }$ & & & $\sqrt{ }$ & $\sqrt{ }$ & $\sqrt{ }$ & $\sqrt{ }$ \\
\hline & & RG & & & & & & & & & & $\sqrt{ }$ & & $\sqrt{ }$ & & & $\sqrt{ }$ & & & & & \\
\hline & & TS & & & & & & & & & & & & & & & & & & & & \\
\hline & & STS & & & & & & & & & & & & & & & & & & & & \\
\hline
\end{tabular}

Tabel. 6 Data Hasil Angket Respon Siswa

\begin{tabular}{|c|c|c|c|c|}
\hline No. & \multirow{6}{*}{ 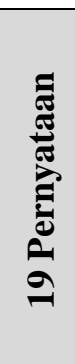 } & Pilihan Penilaian & $\begin{array}{c}\text { Jumlah } \\
\text { Pilihan } \\
\text { Responden }\end{array}$ & $\begin{array}{c}\text { Persentase } \\
(\%)\end{array}$ \\
\hline 1 & & Sangat Setuju/SS & 122 & $32.10 \%$ \\
\hline 2 & & Setuju/ST & 223 & $58.68 \%$ \\
\hline 3 & & Ragu-ragu/RG & 31 & $8.15 \%$ \\
\hline 4 & & Tidak Setuju/TS & 1 & $0.26 \%$ \\
\hline 5 & & Sangat Tidak Setuju/STS & 0 & $0 \%$ \\
\hline
\end{tabular}

Berdasarkan data hasil angket respon siswa diatas yang berjumlah 20 responden, maka dapat diketahui bahwa pilihan penilaian responden terhadap media pictures movement dengan pilihan penilaian pada (Sangat Setuju/SS) sebanyak 122 pilihan, (Setuju/ST) sebanyak 223 pilihan, (Ragu-ragu/RG) sebanyak 31 pilihan, (Tidak Setuju/TS) sebanyak 1 pilihan, dan (Sangat Tidak Setuju/STS) sebanyak 0 pilihan.

SIMPULAN

Penilaian pengembangan media pictures movement untuk pembelajaran menulis paragraf siswa kelas XII SMA Islam Miftahul Ulum ini ditentukan dengan nilai minimal B (Baik). Jadi jika nilai rerata dari ahli materi, ahli media, pengguna, guru, dan tanggapan siswa memperoleh nilai $\mathrm{B}$, maka pengembangan media pictures movement untuk pembelajaran menulis paragraf siswa kelas XII SMA Islam Miftahul Ulum ini dianggap "layak digunakan".

Berdasarkan hasil penelitian dan pembahasan, maka diperoleh nilai rerata yaitu ahli media 1 dan 2 dengan rerata nilai 4.00/4.15 mendapatkan kategori "Baik", untuk ahli materi yaitu dengan rerata nilai 4.22 mendapatkan kategori "Sangat Baik", pengguna 1 dan 2 
dengan rerata nilai 4.16/4.06 mendapatkan kategori "Baik". Sedangkan respon guru yang menggunakan media tersebut menyampaikan bahwa guru tersebut merasa terbantu dalam pemberian materi menulis paragraf kepada siswa karena media pictures movement ini adalah media elektronik yang fleksibel dan variatif sehingga pembelajaran tidak monoton dan tercipta kelas yang kondusif, menyenangkan serta praktis serta tanggapan dari siswa sendiri pada pilihan penilaian memilih ST (Setuju) dengan jumlah pilihan responden sebanyak 223 dengan persentase $58.68 \%$. Jadi nilai rerata dari ahli materi, ahli media, pengguna, guru, dan tanggapan siswa sudah memenuhi kualifikasi yang menjadi acuan peneliti untuk kelayakan media pictures movement. Maka dari itu, pengembangan media pictures movement untuk pembelajaran menulis paragraf siswa kelas XII SMA Islam Miftahul Ulum ini dianggap "Layak Digunakan".

\section{DAFTAR PUSTAKA}

Agustina, Candra. 2015. "Pengembangan Media Pembelajaran Teknik Animasi 2 Dimensi Berbasis Adobe Flash Untuk Siswa Kelas XI Multimedia di SMK Muhammadiyah Prambanan". Skripsi. Universitas Negeri Yogyakarta.

Ahmad, Pribadi Benny dan Yuni Katrin. 2017. Media Teknologi. Jakarta: Universitas Terbuka.

Anita, Ria. 2016. "Pengembangan Media Pembelajaran Teks Anekdot Berbasis Animasi Pada Siswa Kelas X Sekolah Menengah Kejuruan". Tesis. Universitas Lampung.

Angkowo, R. 2007. Optimalisasi Pembelajaran. Jakarta: PT. Grasindo.

Antonius, Rachmat dan Alphone Roswanto. 2005/2006. Pengantar Multimedia. Universitas Kristen Duta Wacana.

Arsyad, Azhar. 1997. Media Pembelajaran. Jakarta: PT. Raja Grafindo Persada.

$$
\text { 2007. Media }
$$

Pembelajaran. Jakarta: PT. Raja Grafindo Persada.
2016. Media Pembelajaran. Jakarta : PT. Raja Grafindo Persada.

Chulsum, Umi dan Windy Novia. 2006. Kamus Besar Bahasa Indonesia $(K B B I)$. Surabaya: Kashiko Surabaya.

Cahyanai Isah, Hodijah. 2007. Kemampuan Berbahasa Indonesia di Sekolah Dasar. Bandung: UPI Press.

Djamarah \& Zain. 2006. Strategi Belajar Mengajar. Jakarta: Rineka Cipta.

Fathurrohman, Pupuh. 2007. Strategi Belajar Mengajar. Bandung: PT Refika Aditama.

Ibrahim dan Syaodih. 1992. Perencanaan Pengajaran. Depdikbud.

Iskandar. 2009. Metode Penelitian Kualitatif. Jakarta: Gaung Persada Press.

Musfiqon. 2012. Pengembangan Media Dan Sumber Pembelajaran. Jakarta: PT. Prestasi Pustakaraya.

Nurgiyantoro, Burhan. 1995. Teori Pengkajian Fiksi. Yogyakarta: Gadjah Mada University Press. 
Poerwadarminta, W.J.S. 1979. $A B C$ Karang Mengarang. Yogyakarta : Gadjah Mada University.

Putri, Anisa Windari Septiani. 2016. "Pengembangan Media Pembelajaran Video Animasi 2D Berbasis Multimedia Menggunakan Adobe Flash CS6 Pada Mata Pelajaran Bahasa Indonesia Kelas III SD”. Skripsi. Universitas Pgri Yogyakarta.

Rusyana, Yus. 1986. Buku Materi Pokok Keterampilan Menulis. Jakarta : Karunia.

Rima Wati, Ega. 2016. Ragam Media Pembelajaran. Yogyakarta : Kata Pena.

Siti Mariah Ulfah, 2016, Animasi 2 Dimensi (pengertian animasi, Teknik animasi), sitimariahulfah.ilearning.me/2016 /04/20/animasi-2 dimensipengertian-animasi-teknikanimasi/ diakses tanggal 5 Januari 2018).

Soeharto, Karti \& dkk. 2003. Tehnologi Pembelajaran (Pendekatan Sistem, Konsepsi dan Model, SAP, Evaluasi, Sumber Belajar Media). Surabaya: Surabaya Intelectual Club.

Sugiarta, Awandi Nopyan. 2007. Pengembangan Model Pengelolaan Program Pembelajaran Kolaboratif untuk Kemandirian Anak Jalanan dirumah Singgah (Studi Terfokus dirumah Singgak Kota Bekasi). Bandung : PPS UPI.

Suriamiharja, Agus dkk. 1996. Petunjuk Praktis Menulis. Jakarta:
Departemen Pendidikan dan Kebudayaan Direktorat Jenderal Pendidikan Dasar Dan Menengah bagian Proyek Penataran Guru SLTP Setara D-III.

Suheri, Agus. 2006. Animasi Multimedia Pembelajaran. Jakarta: Elec media Komputindo.

Sugiyono. 2011. Metode Penelitian Kuantitatif Kualitatif $R \& D$. Bandung : Alfabeta.

2012. Prosedur Penelitian Suatu Pendekatan Praktik. Jakarta: PT. Rineka Cipta.

2015. Metode Penelitian \& Pengembangan. Bandung: Alfabeta.

Sulaiman, $\quad$ Abdu. 2015. http://abdusulaiman.blogspot.co.i d/2015/12/macam-macam-teknikanalisis-data.html? $\mathrm{m}=1$ diakses pada tanggal 20 Januari 2018.

Tarigan, Henri Guntur. Membaca sebagai suatu keterampilan berbahasa. Bandung: Angkasa.

Tegeh, I Made, dkk. 2014. Model Penelitian Pengembangan. Yogyakarta: Graha Ilmu.

Usman, Husaini dan Purnomo Setiady Akbar. 2011. Penelitian Pendidikan. Bandung: Remaja Rosda Karya.

Wibawa, Basuki \& Farida Mukti. 1992. Media Pendidikan. Jakarta: Depdikbud.

Widoyoko, Eko Putro. 2009. Evaluasi Program Pembelajaran. Yogyakarta: Pustaka Belajar. 